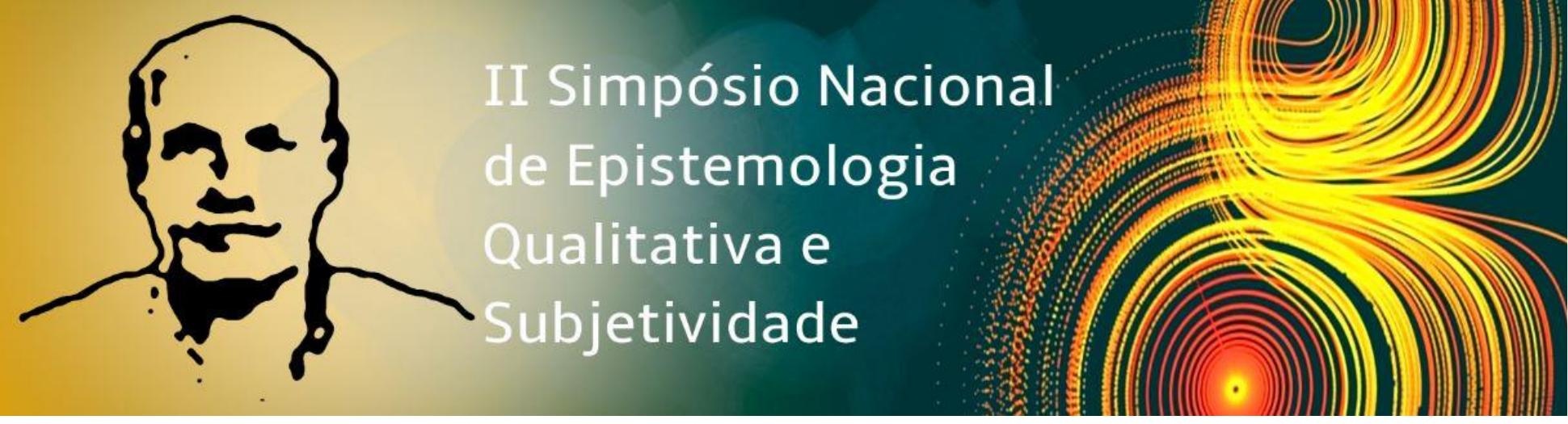

\title{
O UNIVERSITÁRIO COM DEFICIÊNCIA VISUAL COMO SUJEITO DE SEU DESENVOLVIMENTO
}

Danielle Sousa da Silva, Universidade de Brasília, dssfatima@gmail.com Maristela Rossato, Universidade de Brasília, maristelarossato@gmail.com

Este estudo tem o objetivo geral de compreender como o universitário com deficiência visual se constitui sujeito de seu desenvolvimento. A pesquisa foi realizada à luz da Perspectiva Histórico-Cultural, e o percurso metodológico, inspirado no caráter construtivo-interpretativo da Epistemologia Qualitativa de González Rey. Participaram deste estudo uma universitária cega oriunda de uma Instituição de Ensino Superior localizada no Distrito Federal, Brasil, aqui denominada de Maria. A análise preliminar possibilitou compreender que a pessoa cega vivencia tensões e dramas ao longo do seu ciclo vital, na relação entre a subjetividade individual e a subjetividade das instituições sociais, que viabilizam experiências promotoras de desenvolvimento. Esta compreensão sinaliza o valor heurístico desta pesquisa em contrapor-se à tendência de associar a excelência do processo de inclusão das pessoas com deficiência no ensino superior estritamente às condições legais de acesso, permanência e conclusão. Volta, assim, o olhar para a constituição do desenvolvimento subjetivo da pessoa com deficiência visual em meio às suas experiências e vivências acadêmicas até a chegada e permanência no ensino superior.

Palavras chave: Desenvolvimento humano. Deficiência visual. Subjetividade. 


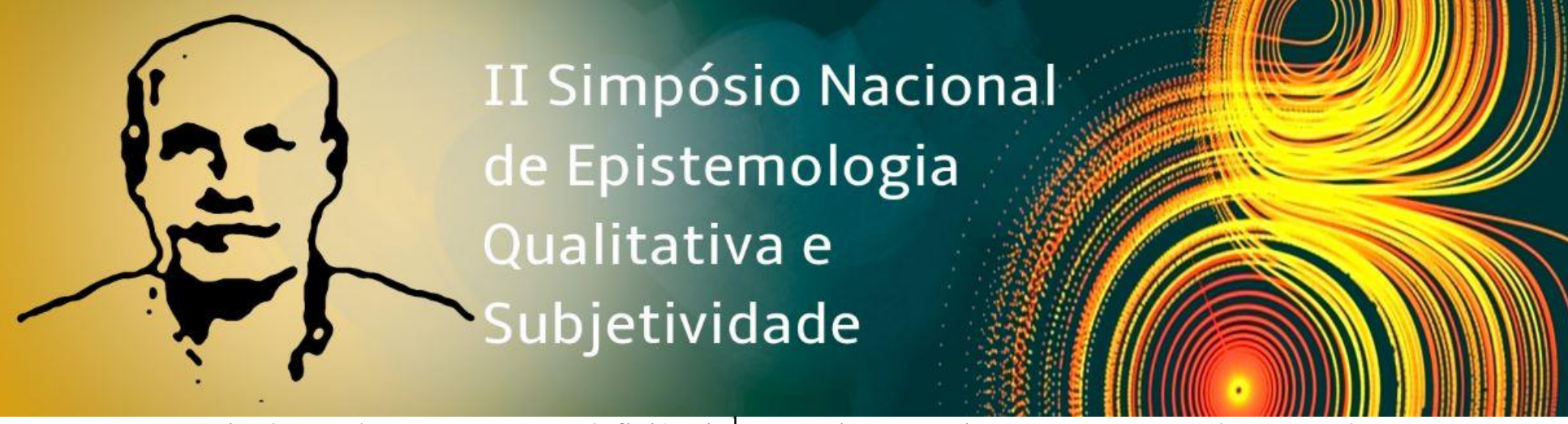

A inclusão das pessoas com deficiência ${ }^{1}$ no ensino superior tem representado, segundo

Rodrigues Fernandes (2015, p. 17), “[...] um importante desafio, que se manifesta de modo peculiar nos diferentes níveis e modalidades de ensino, em instituições públicas ou privadas”.

Os desafios vão desde questões pedagógicas até as dinâmicas subjetivas (aspectos simbólicoemocionais), as dinâmicas interpessoais (estudante com deficiência versus estudante sem deficiência; estudante com deficiência versus professor; estudante com deficiência versus núcleos de acessibilidade, entre outras configurações) e as especificidades de cada deficiência perante as peculiaridades de cada nível e modalidade do ensino superior (graduação, especialização, pós-graduação lato sensu e stricto sensu).

Segundo dados do IGBE (2010), no Brasil existem 190.732.694 pessoas; destas, 6,5 milhões são deficientes, sendo 35.791 .488 deficientes visuais. ${ }^{2}$ Destes, 528.624 não conseguem ver de modo algum e são considerados cegos e 6.056.684 apresentam grande dificuldade de ver, sendo consideradas pessoas com baixa visão. Já os dados referentes aos estudantes com deficiência autodeclarada no ensino superior brasileiro registram o contingente de 33.377, entre cursos de graduação presencial e a distância, conforme as Sinopses Estatísticas da Educação Superior de 2014 (Inep, 2014). ${ }^{3}$ As deficiências

\footnotetext{
${ }^{1}$ Neste trabalho, adotaremos a expressão "pessoa com deficiência", pois exprime a característica individual na interação social, apesar de Diniz (2007, p. 10) sinalizar que "o movimento crítico mais recente opta por 'deficiente' como uma forma de devolver os estudos sobre a deficiência ao campo dos estudos culturais e de identidade". Além disso, compreende-se a categoria "deficiente" como um mecanismo de identidade, em contraste com os conceitos de "pessoa não deficiente" ou "não deficiente" (Diniz, 2007, p. 11).

${ }^{2}$ Os dados do último Censo Demográfico realizado no Brasil datam de 2010, porque o censo é realizado a cada 10 anos. Dados parciais do IBGE (2017) revelam que a população brasileira já atingiu o quantitativo de 207.660.929 habitantes. Contudo, não existem dados mais recentes do contigente de pessoas com deficiência visual no país.

${ }^{3}$ Utiliza-se o termo "autodeclaradas" para enfatizar que se trata de uma porcentagem de estudantes que, no ato da matrícula no ensino superior, se declararam pessoa com deficiência, apresentando documentos comprobatórios. No entanto, há muitos estudantes com algum tipo de deficiência que optam por não se declararem como tais, por isso não adentram os índices numéricos de universitários com deficiência.
} 


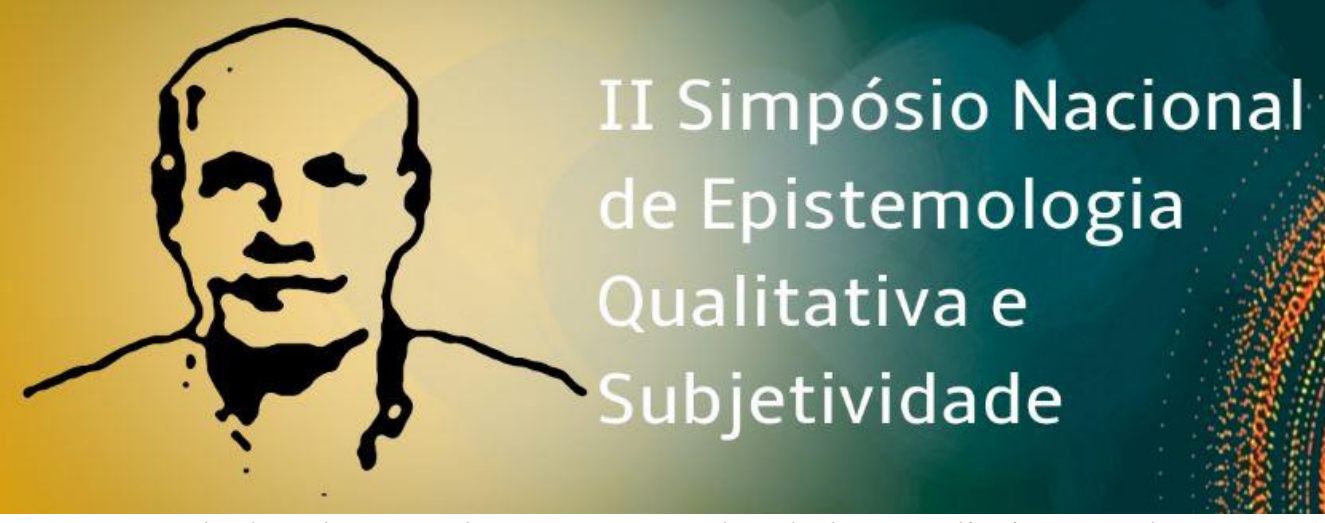

autodeclaradas atualmente, segundo dados preliminares do Inep (2014), diferem entre cegueira, baixa visão, surdez, deficiência auditiva, deficiência física, surdo-cegueira, deficiência múltipla, deficiência intelectual, autismo, síndrome de Asperger, síndrome de Rett, transtorno desintegrativo da infância e superdotação. Na Região Centro-Oeste, ainda segundo os dados do Inep (2014), há 2.683 pessoas autodeclaradas com alguma deficiência e/ou necessidade especial. Destas, 186 se declararam com cegueira e 869 se declararam com baixa visão (Inep, 2014).

Pensando acerca nas condições de enfretamento adotadas por universitários deficientes visuais ao longo do seu processo de escolarização, observa-se a necessidade de desmistificar a relação imediata entre as condições de acesso e o processo de inclusão, reconhecendo assim que o processo de inclusão da pessoa com deficiência visual no ensino superior é acrescido de presenças afetivas e experiências oriundas da sua trajetória pessoal de vida que o possibilitam constituir-se enquanto sujeito do seu desenvolvimento. Desta maneira, adverte-se que a inclusão vai além de garantir acesso, permanência e conclusão do ensino superior. Conforme discute Oliveira (2005, p. 61), é necessário considerar as trajetórias de desenvolvimento (típico ou atípico) adulto, que revelam "uma história mais longa (e provavelmente mais complexa) de experiências, conhecimentos acumulados e reflexões sobre o mundo externo, sobre si mesmo e sobre as outras pessoas".

Na ocasião da eleição da temática a ser estudada nesta pesquisa, emergiram as seguintes indagações: como a experiência acadêmica permeia a trajetória desenvolvimental do estudante com deficiência visual? Desdobrando essa questão, tem-se: quais significados são produzidos acerca do processo de escolarização da pessoa com deficiência visual? O que 


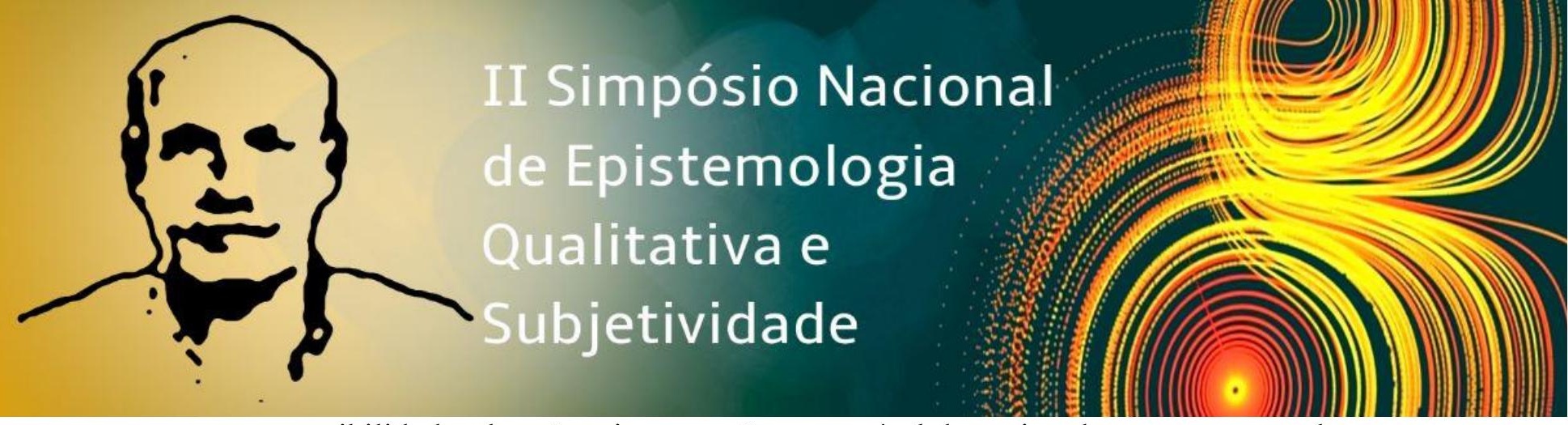

pensar novas possibilidades de ação e intervenção neste nível de ensino, bem como em todo o

processo de escolarização da pessoa com deficiência visual.

\section{Reflexões da Perspectiva Histórico-Cultural para o estudo da pessoa com deficiência visual}

O estudo das pessoas com deficiência visual aparece em diferentes momentos da produção intelectual de Vigotski, sobretudo quando há uma discussão sobre os princípios gerais da educação das pessoas com deficiência, bem como em diferentes capítulos de Fundamentos de defectologia (Vigotski, 1997).

Sobre o desenvolvimento e a educação de cegos, Vigotski evidencia uma posição contrária à compreensão de compensação biológica, seja pelo tato, seja pela audição (Nuernberg, 2008). Isso porque "a cegueira é uma condição normal e não patológica para a criança cega, e ele a percebe apenas indiretamente, secundariamente, como resultado de sua experiência social refletida nela" (Vigotski, 1997, p. 79). ${ }^{4}$ Essa discussão consolida a ideia de que o problema da deficiência influi no social, como está delimitado na deficiência secundária.

Na pessoa com deficiência visual, esse processo estabelece relação com o princípio de mediação semiótica do funcionamento psíquico, que sustenta a premissa de que "a constituição subjetiva de uma pessoa diagnosticada como cega está influenciada pelo contexto ideológico e cultural em que se situa historicamente, mesmo que não seja em uma dependência causal direta” (Raposo \& Mitjáns Martínez, 2011, p. 252). Diante desta via de

\footnotetext{
${ }^{4}$ Texto original: "la ceguera es un estado normal y no patológico para el niño ciego, y él lo percebe solo indirectamente, secundariamente, como resultado de su experiencia social reflejada en él”.
} 


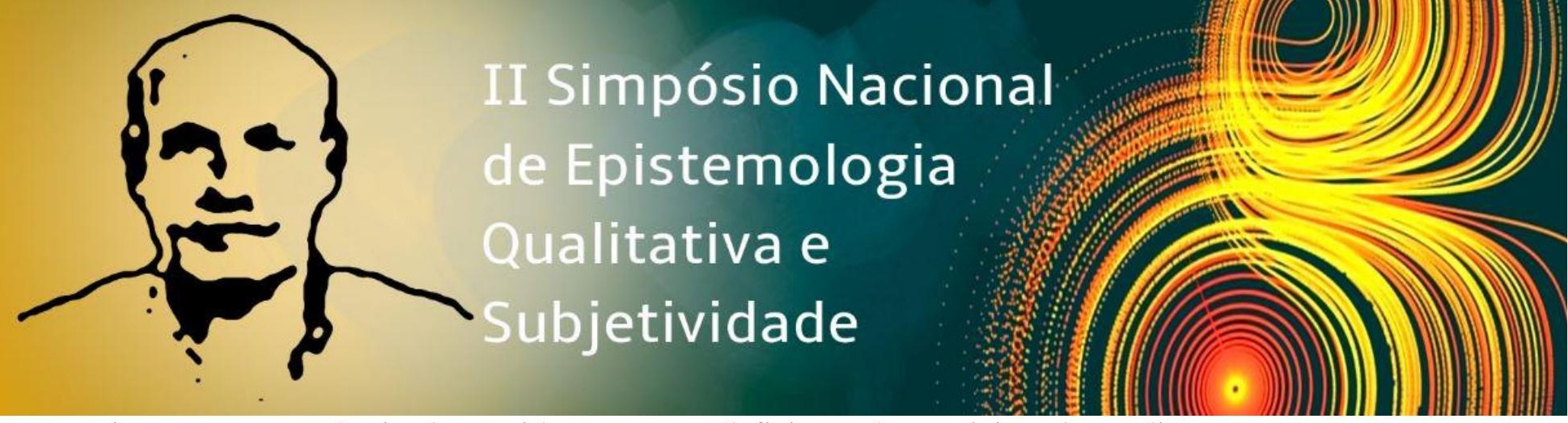

vista que, na ausência de sentido, a pessoa deficiente é reposicionada mediante processos compensatórios, seja pela diversidade das operações que podem ser realizadas pelas funções cognitivas, seja pelo segundo caminho, que compreende a participação da coletividade em influir nas funções psicológicas superiores (Vigotski, 1997).

Assim, considera-se que as estratégias de inclusão social para a pessoa com deficiência visual devem congregar, além das palavras, as novas tecnologias como via de acesso às informações e ao conhecimento (Silva, 2013), além da emergência de compreender como a pessoa com deficiência visual é simultaneamente constituída pela articulação entre a subjetividade individual e subjetividade social. Isto porque "a cegueira é não apenas um defeito, uma deficiência, uma fraqueza como também, em certo sentido, uma fonte de revelação de habilidades, uma vantagem, uma força (por mais estranho e paradoxal que isso soe!)” (Vigotski, 1997, p. 99). ${ }^{7}$ Essas características só são visíveis, segundo González Rey (2011, p. 245), quando em contato com "as produções de sentidos subjetivos que posicionam a pessoa, dinamicamente, na linha defeito/compensação".

\section{Sujeito e subjetividade na Perspectiva Histórico-Cultural}

Gonzaléz Rey (2003) em seus estudos acerca da definição de sujeito faz um apanhado de diferentes perspectivas teóricas. Inicialmente "a ideia de sujeito esteve ligada a um princípio universal de integibilidade, consciência e ordem [...], fortemente influenciadas pelo racionalismo cartesiano" Gonzaléz Rey (2003, p. 221), que faz alusão a um sujeito universal e ideal, que em síntese revela uma representação passiva. Essa visão de sujeito se contrapõe a perspectiva da fenomenologia de Husserl, que considera que o sujeito tem um papel ativo e

\footnotetext{
7 Texto original: "la ceguera es no solo un defecto, una deficiencia, una debilidad, sino también, en cierto sentido, una fuente de revelácion de aptitudes, una ventaja, u a fuerza (por extraño y similar a u a paradoja que esto suene!)".
} 


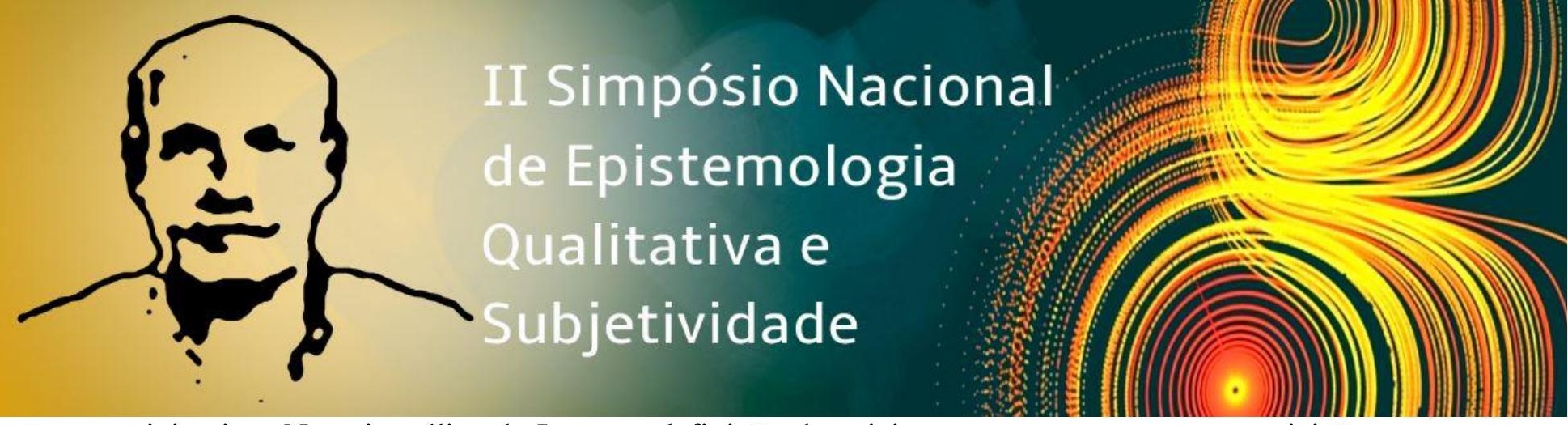

participativo. Na psicanálise de Lacan a definição de sujeito aparece enquanto uma sujeição do sujeito na ordem da linguagem (Gonzaléz Rey, 2003, p. 228). Já no marxismo, pela primeira vez, o sujeito é associado à ideia de um sujeito concreto, "em sua condição atual a síntese de sua história social, não como acumulação, mas como expressão de uma nova condição, [...] em que a formação da psique se constitue dentro do espaço histórico-cultural do homem" Gonzaléz Rey (2003, p. 222).

Essa compreensão material acerca da compreensão do sujeito motivou González Rey (2003) a partir de Touraine (1999) a tecer duas ideias centrais, sendo a primeira de que a categoria sujeito não foi definida dentro do espaço histórico e dos entraves composto pela modernidade, e em segunda instância, Touraine (1999) "resgata o mundo interno do sujeito afirmando que o sujeito é constituído subjetivamente, é um sujeito subjetivado com capacidade de subjetivação de sua experiência, na qual não se dilui em nenhum dos sistemas que participam de seu desenvolvimento” (González Rey, 2003, p. 224). Desta maneira, a compreensão do sujeito está atrelada a uma concepção dialética do homem, onde "o homem de forma simultânea representa singularidade e um ser social, relação esta que não é uma relação de determinação externa, mas uma relação recursiva em que cada um está simultaneamente implicado na configuração plurideterminada dentro da qual se manifesta a ação do outro" (González Rey, 2003, p. 224).

Com base nisto, este estudo pretende discursar sobre a compreensão de sujeito, diferenciando-o da concepção de agente, sob a ótica da Teoria da Subjetividade proposta por González Rey e Martínez (2017a). A definição de sujeito sob a égide desta teoria compreende aquele indivíduo ou grupo capaz de abrir novos caminhos de subjetivação dentro do espaço normativo de sua ação, e o termo agente é reservado para as posições ativas 


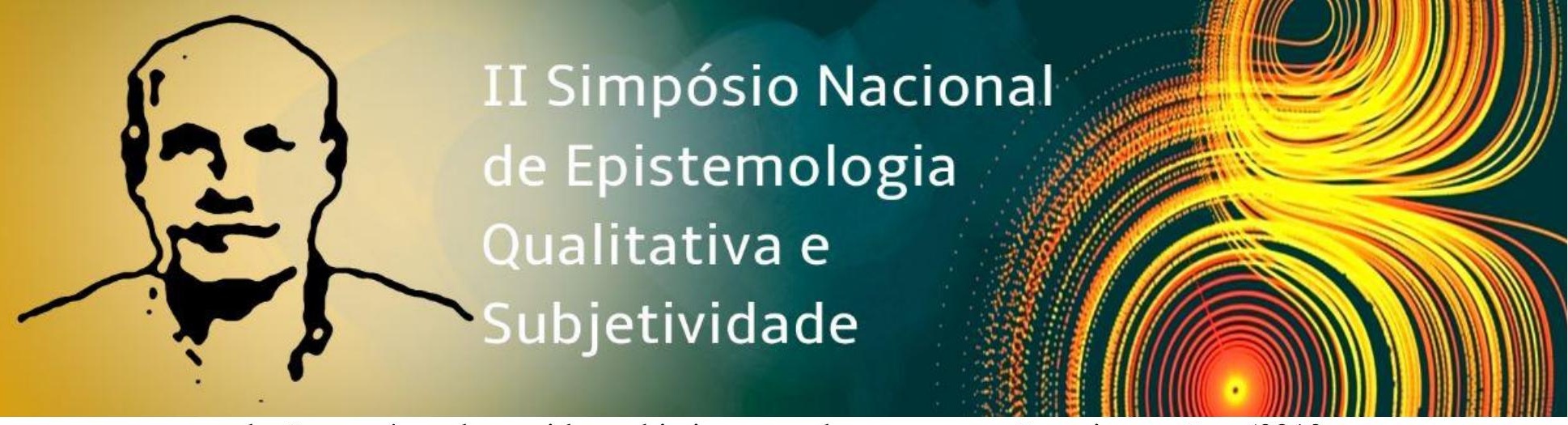

produção contínua de sentidos subjetivos gerados em suas ações e interações. (2013, p.

404)

Diante do reconhecimento do caráter ativo, reflexivo e criativo do sujeito em relação ao social, e de sua inserção em um estado de "tensão e rupturas, podendo gerar novas unidades de subjetivação individual e social” (Rossato \& Mitjáns Martínez, 2011 p. 290), sua constituição configura-se como aspecto essencial do desenvolvimento humano. É perante as possibilidades de contradição que podemos ser, além de atribuir novos sentidos e ampliar a compressão das experiências.

Neste sentido, as tensões existentes ao longo do desenvolvimento integram novas produções subjetivas às suas experiências e práticas sociais, mediante a necessidade de mudança. Consequentemente, compreende-se o desenvolvimento como algo processual, dinâmico, um sistema em movimento, atento às situações que se constituem como promotoras ou não de desenvolvimento (Rossato \& Mitjáns Martínez, 2013).

Desta maneira, os posicionamentos e as mudanças a serem assumidos pelo sujeito nas experiências sociais nos levam a refletir sobre os tensionamentos produzidos entre a subjetividade individual e a subjetividade social, aspecto que sinaliza que as mudanças, rupturas e opções assumidas, em conformidade com González Rey \& Mitjáns Martínez, (2017b), ocorrem nestes dois níveis simultaneamente, o social e o individual. No que tange ao conceito de subjetividade social, destaca-se que

representa complexa rede de configurações subjetivas dentro das quais todo funcionamento social tem lugar. Esses processos acontecem sem que os participantes que compartilham esses espaços tomem consciência deles. A subjetividade social 


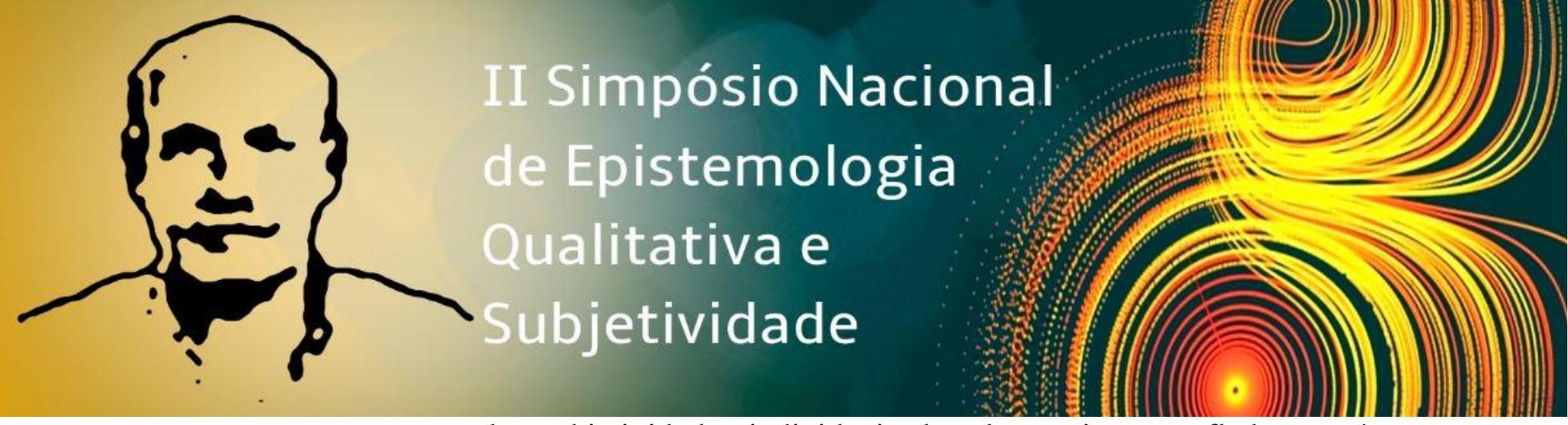

emerge como parte das subjetividades individuais de tal maneira camuflada que é impossível inferi-la diretamente dos comportamentos observados ou da linguagem explícita. (González Rey, 2015, p. 13)

Reside nesta articulação entre individual e social a existência constitutiva da pessoa como sujeito, incluindo ainda as possibilidades de atuação ativa mediante as capacidades “inovadoras, criadoras, reflexivas que proporcionaram novos caminhos a serem percorridos e novos espaços de subjetivação” (González Rey \& Mitjáns Martínez, 2017b, p.73).

Reforça-se o lugar que o sujeito ocupa no seu processo de desenvolvimento como ser ativo, motivado a ir além dos espaços sociais normativos, imbuído da capacidade consciente e do exercício constante de refletir sobre a construção de sua subjetivação. Isto evoca a existência de opções criativas, que se "configuram subjetivamente no sujeito e na subjetividade social em que a ação se desenvolve" (González Rey \& Mitjáns Martínez, 2017b, p. 73-74).

\section{Pressupostos Metodológicos}

Esta pesquisa está organizada por meio de estudo de caso com uma universitária com deficiência visual, especificamente, cega. A pesquisa tem o objetivo geral de compreender como o universitário com deficiência visual se constitui sujeito de seu desenvolvimento. Os objetivos específicos são de analisar: a) como as experiências vivenciadas ao longo da vida podem ter mobilizado a constituição de recursos simbólico-emocionais que possibilitaram o ingresso e a permanência no ensino superior.

Assim, por meio da relação dialógica foi possível produzir indicadores de sentidos subjetivos associados às experiências relatadas pelos participantes, sinalizando a influência 


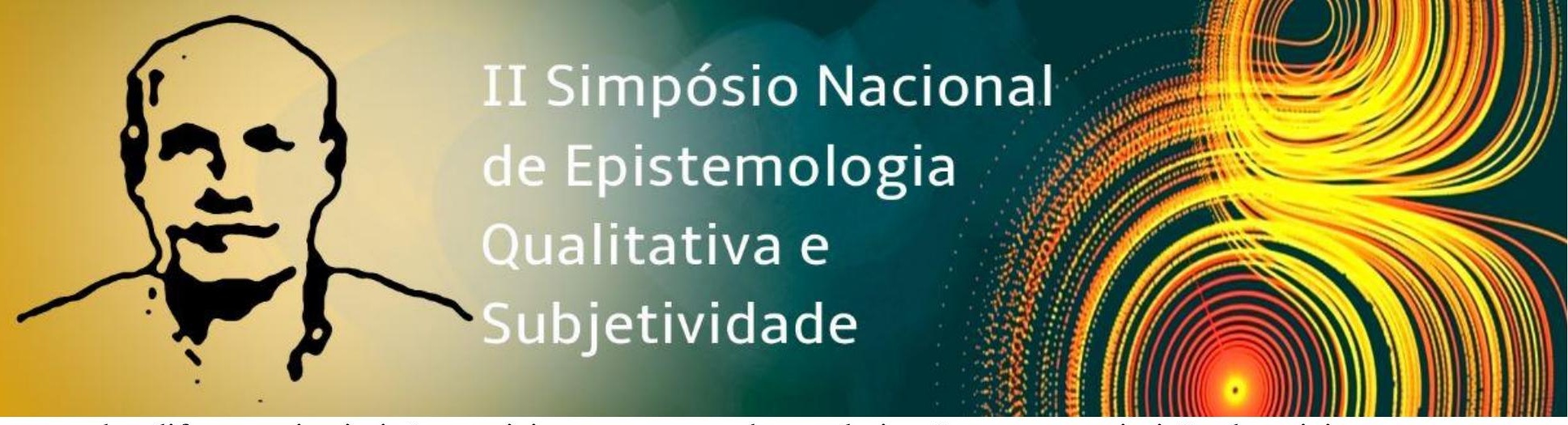

das diferentes instituições sociais no processo de escolarização e na constituição do sujeito.

Além disso, a proposição desta pesquisa tece abertura para um novo campo de inteligibilidade sob a ótica da Epistemologia Qualitativa, uma vez que vai ao encontro de investigações que reconhecem as dimensões sociais e institucionais como desencadeadoras das problemáticas enfrentadas no processo de inclusão do universitário com deficiência visual. Além disso, sinaliza a urgência de considerar as contribuições singulares dos sujeitos nas proposições teóricas e práticas que têm sido pensadas para este público.

Para responder ao ordenamento teórico empregado neste estudo, foram utilizados os procedimentos de construção da informação da Pesquisa Construtivo-Interpretativa com a finalidade de compreender a complexidade da realidade das pessoas com deficiência visual no ensino superior. Em consonância com a proposta teórico-metodológica adotada, não se reconhece a realidade como uma dimensão estática, mas sim como uma produção dinâmica, criativa e inesgotável do saber (Oliveira, 2017).

Sob esta ótica epistemológica, reconhecem-se os significados e sentidos produzidos singularmente no contexto cultural e nas vivências dos universitários com deficiência visual, o que nos leva a observar a incoerência de generalizar a experiência da cegueira ou baixa visão no âmbito do ensino superior. Com base nisto, entende-se que a produção de indicadores, por parte do pesquisador, abrange um processo criador, que possibilita elaborar caminhos interpretativos sobre a constituição do sujeito revelados a partir das expressões e da interação dos participantes.

Nesta pesquisa, os instrumentos utilizados para a produção de informação foram os sistemas relacionais conversacionais, uma vez que "possibilita[m] ao pesquisador deslocar-se do lugar central das perguntas para integrar-se em uma dinâmica de conversação que toma

\section{BRASÍLIA, 22 a 25 DE OUTUBRO DE 2019 CENTRO UNIVERSITÁRIO DE BRASÍLIA - UNICEUB}




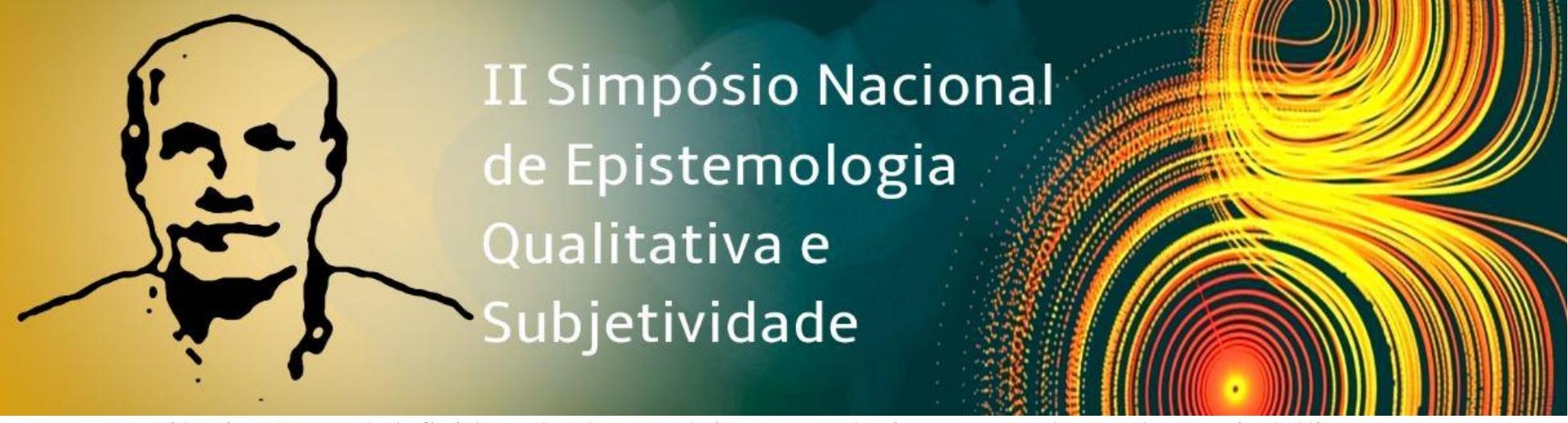

experiência não está definida pelo desenvolvimento psíquico, mas pela produção simbólico-

emocional gerada ante essa experiência” (2017a, p. 8). ${ }^{9}$ Em complemento a isto, e em contraste com a proposta de Wallon, González Rey entende que a "psique como reflexo das condições objetivas não permite pensar em um psiquismo caracterizado pela produção" (2011, p. 58) subjetiva, simbólica e emocional, o que reflete a necessidade de potencializar o indivíduo perante as experiências que se apresentam em seu desenvolvimento.

Assim, ao observar as vivências relatadas por Maria, verifica-se que o seu processo de desenvolvimento não se constituiu de uma maneira linear, e tampouco foi modelado estritamente de fora para dentro. Destaca-se, à luz de González Rey, como “o resultado de um sistema de relações que permite o engajamento da pessoa como sujeito e que reconhece possibilidades múltiplas de expressão nesse processo, isto porque, sem os posicionamentos da pessoa, o desenvolvimento não acontece” (2011, p. 59).

A segunda hipótese relaciona-se à necessidade de mobilizar sentidos subjetivos em prol da emergência do sujeito. Em face das hipóteses elaboradas por meio dos indicadores produzidos a partir das experiências de Maria, verifica-se que o acesso e a permanência de Maria no ensino superior revelam uma trajetória de desenvolvimento em que foram mobilizados sentidos subjetivos em prol da emergência do sujeito, aspecto já sinalizado no trabalho de Raposo e Mitjáns Martínez (2011) sobre a educação dos alunos com deficiência visual.

Amalgamado a isto, revela-se o mecanismo de compensação sinalizado por Vigotski (1997), sobretudo no que tange à compreensão de que a deficiência "pode se constituir numa

\footnotetext{
9 Texto original: "la dimensión de sentido subjetivo producida por una experiencia no está definida por el desarollo psíquico, sino por la producción simbólico-emocional generada ante esa experiencia”.
} 


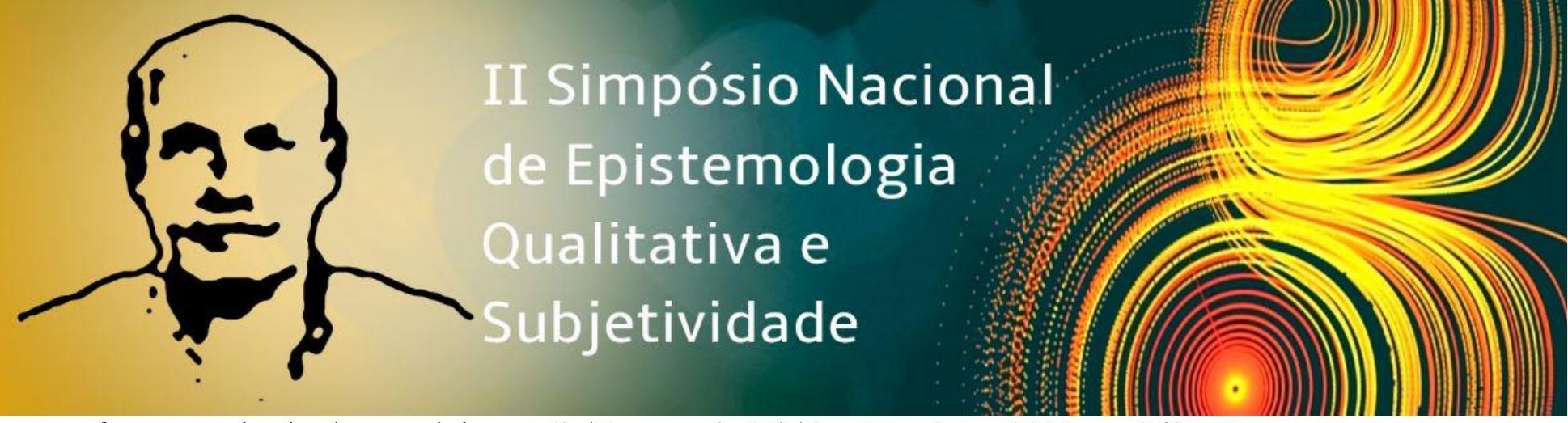

força motriz de desenvolvimento" (Raposo \& Mitjáns Martínez, 2011, p. 269). Para tanto, apesar de a deficiência assumir uma condição capaz de potencializar o desenvolvimento, isto não está atrelado, como já dito, a sentidos subjetivos relacionados à sensação de bem-estar, mas à ideia dos tensionamentos e confrontos que são capazes de produzir novos sentidos diante do outro ou das situações, conforme explicitado nos relatos de Maria.

Rossato (2009), em sua tese de doutorado, discute as repercussões das dificuldades de aprendizagem no desenvolvimento humano, que podem culminar em problemas de aprendizagem ante a negação das instituições sociais, com destaque para a família. Desta maneira, reconhece-se a relevância das relações interpessoais do indivíduo em motivar espaços simbólico-emocionais que the possibilitem se "colocar como sujeito de sua aprendizagem" (p. 179) e, também, de seu desenvolvimento.

Em síntese, corroborando Araújo, Oliveira e Rossato, compreende-se que "o sujeito configura-se no diálogo - com os outros e consigo mesmo -, de acordo com uma dinâmica complexa e imbricada, que se desenrola no tempo e no espaço sempre mediada por signos da cultura" (2017, p. 6).

\section{Referências}

Anache, A. A. (2009). A epistemologia qualitativa: contribuições para a pesquisa em educação especial. InterMeio, 15(30), 123-141. Disponível em http://seer.ufms.br/ojs/index.php/intm/article/view/2460/1628

Araújo, C. M. de, Oliveira, M. C. L. S. de, \& Rossato, M. (2017). O sujeito na pesquisa qualitativa: desafios da investigação dos processos de desenvolvimento. Psicologia: Teoria e Pesquisa, 33. Disponível em https://dx.doi.org/10.1590/0102.3772e33316 


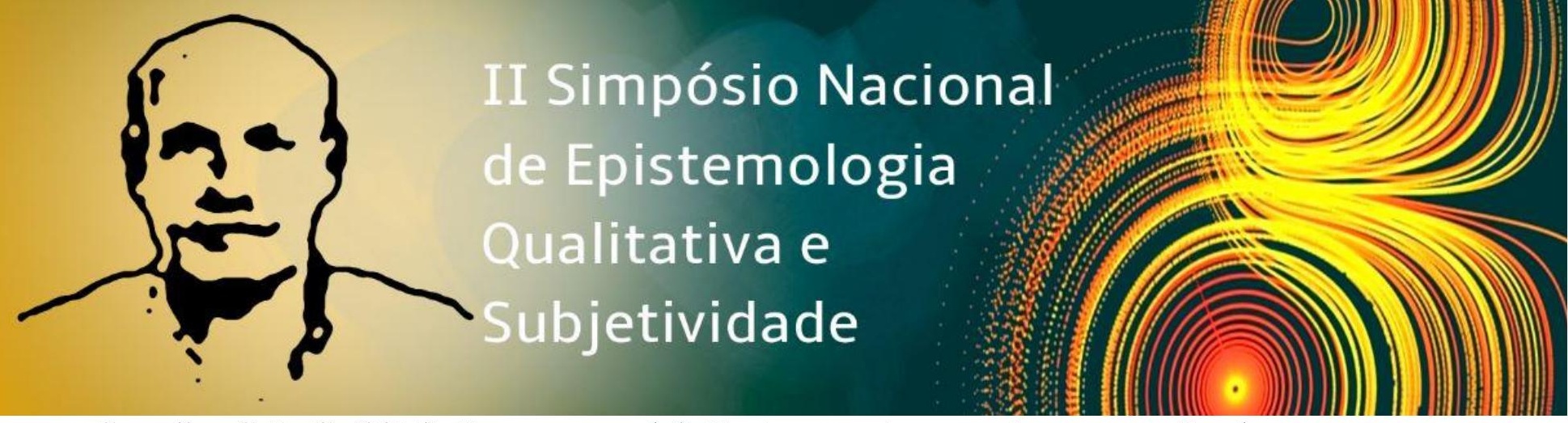

Carvalho, C. L. C. (2015). Pessoas com deficiência no ensino superior: percepções dos alunos (Dissertação). Universidade de São Paulo, São Paulo.

Castro, S. F. de. (2011). Ingresso e permanência de alunos com deficiência em universidades públicas brasileiras (Tese). Universidade Federal de São Carlos, São Carlos. Disponível em https://repositorio.ufscar.br/bitstream/handle/ufscar/2878/3611.pdf?sequence=1\&isAllowed=y.

Daroque, S. C. (2011). Alunos surdos no ensino superior: uma discussão necessária (Dissertação). Universidade Metodista de Piracicaba, São Paulo.

Diniz, D. (2007). O que é deficiência. São Paulo: Brasiliense.

Diniz, D., Barbosa, L., \& Santos, W. R. (2009). Deficiência, direitos humanos e justiça. SURRevista Internacional de Direitos Humanos, 6(11), 65-77. Disponível em http://www.scielo.br/pdf/sur/v6n11/04.pdf

Fernandes, A. C. R. (2015). Dinâmicas de significação e trajetórias de desenvolvimento: experiências de estudantes com deficiência autodeclarada na universidade (Tese). Universidade de Brasília, Brasília.

Gonzáley Rey, F. (2011). Os aspectos subjetivos no desenvolvimento de crianças com necessidades especiais: além dos limites concretos do defeito. In A. Mitjáns Martínez, \& M.

C. V. R. Tacca, Possibilidades de aprendizagem: ações pedagógicas para alunos com dificuldades e deficiência (pp. 47-70). Campinas: Alínea.

González Rey, F. L. (2003). Sujeito e subjetividade. São Paulo: Thomson.

González Rey, F. L. (1997). Epistemología cualitativa y subjetividad. São Paulo: EDUC. 


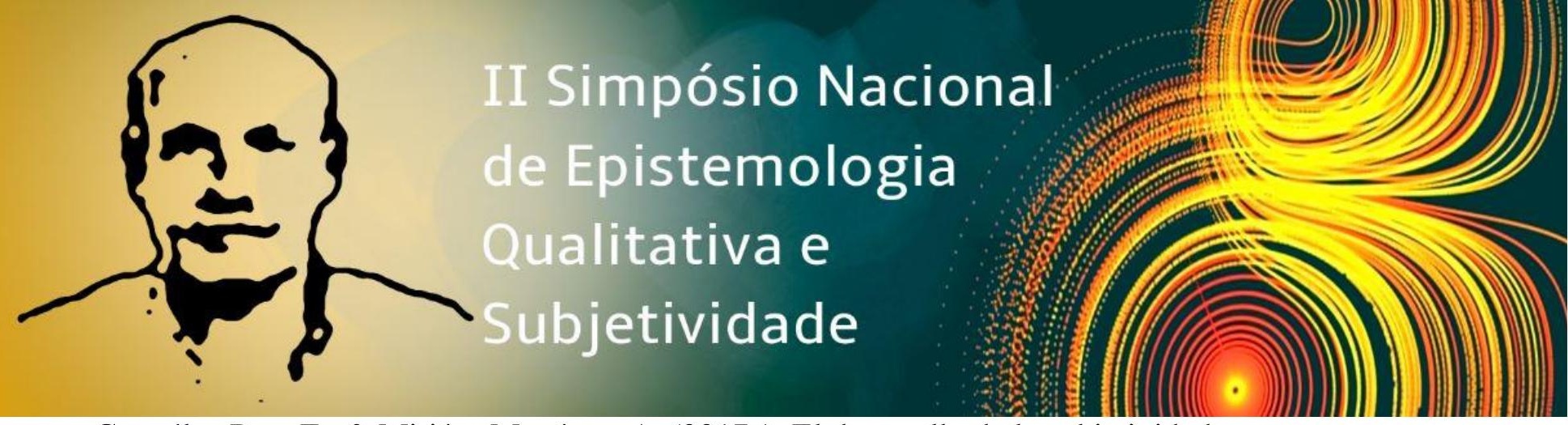

González Rey, F., \& Mitjáns Martínez, A. (2017a). El desarrollo de la subjetividad: una alternativa frente a las teorías del desarrollo psíquico. Papeles de Trabajo sobre Cultura, Educación y Desarrollo Humano, 13(2), 3-20. Disponível em http://psicologia.udg.edu/PTCEDH/menu_articulos.asp.

González Rey, F., \& Mitjáns Martínez, A. (2017b). Subjetividade: teoria, epistemologia e método. Campinas-SP: Alínea.

Guerreiro, E. M. B. R. (2011). Avaliação da satisfação do aluno com deficiência no ensino superior: um estudo de caso da UFSCAR (Tese). Universidade Federal de São Carlos, São Paulo.

Instituto Brasileiro de Geografia e Estatística (IBGE). (2010). Censo Demográfico 2010. Disponível em http://www.censo2010.ibge.gov.br

Instituto Brasileiro de Geografia e Estatística (IBGE). (2017). Resolução $n^{\circ}$ 4, de 28 de agosto de 2017. Disponível em

http://pesquisa.in.gov.br/imprensa/jsp/visualiza/index.jsp?jornal=1\&pagina=58\&data=30/08/2 017

Instituto Nacional de Estudos e Pesquisas Educacionais Anísio Teixeira (Inep). (2015).

Sinopses Estatísticas da Educação Superior 2014. Disponível em http://inep.gov.br/sinopsesestatisticas-da-educacao-superior

Morejón, K. (2009). O acesso e a acessibilidade de pessoas com deficiência no ensino superior público no estado do Rio Grande do Sul (Tese). Universidade de São Paulo, Ribeirão 


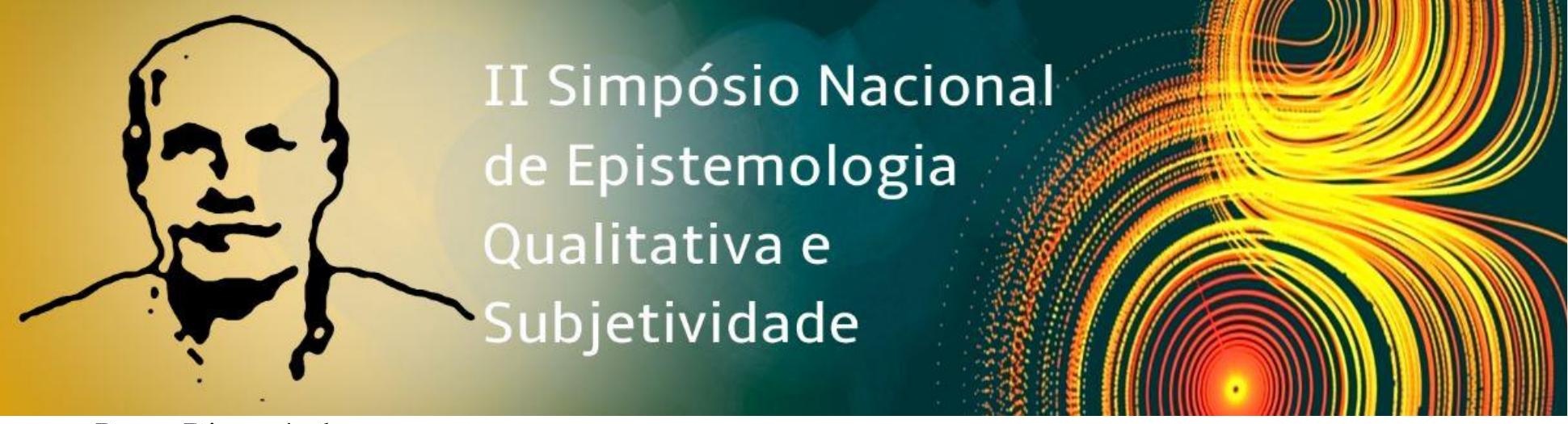

Preto. Disponível em

https://www.ffclrp.usp.br/imagens_defesas/30_05_2011_09_01_45_61.pdf

Nuernberg, A. H. (2008). Contribuições de Vigotski para a educação de pessoas com deficiência visual. Psicologia em Estudo, 13(2), 307-316.

Oliveira, A. M. do C. de. (2017). Desenvolvimento subjetivo e educação: avançando na compreensão da criança que se desenvolve em sala de aula (Dissertação). Universidade de Brasília, Brasília.

Oliveira, M. K. (2005). Jovens e adultos como sujeitos de conhecimento e aprendizagem: educação como exercício de diversidade. Brasília: Unesco, MEC, ANPEd,. (Coleção Educação para Todos, 6).

Raposo, P. N. \& Mitjáns Martínez, A. (2011). A aprendizagem dos alunos com deficiência visual: reflexões a partir de uma pesquisa no ensino superior. In A. Mitjáns Martínez, \& M. C. V. R. Tacca, Possibilidades de aprendizagem: ações pedagógicas para alunos com dificuldades e deficiência (pp. 237-271). Campinas: Alínea.

Rossato, M. (2009). O movimento da subjetividade no processo de superação das dificuldades de aprendizagem escolar (Tese). Universidade de Brasília, Brasília.

Rossato, M., \& Martínez, A. M. (2011). A superação das dificuldades de aprendizagem e as mudanças na subjetividade. In A. Mitjáns Martínez, \& M. C. V. R. Tacca, Possibilidades de aprendizagem: ações pedagógicas para alunos com dificuldades e deficiência (pp. 71-107). Campinas: Alínea. 


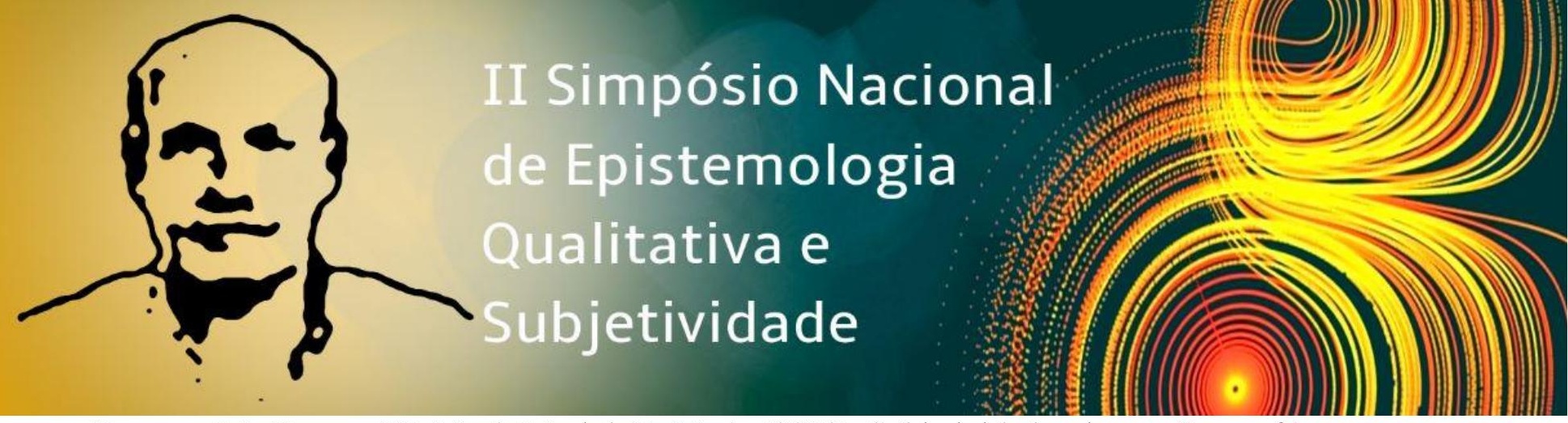

Rossato, M., Ramos, W. M., \& Maciel, D. M. A. (2013). Subjetividade e interação nos fóruns online reflexões sobre a permanência em educação a distância. Revista Reflexão e Ação, 21(2), 399-429. Disponível em https://online.unisc.br/seer/index.php/reflex/article/view/3740/3032

Rossetto, E. (2009). Sujeitos com deficiência no ensino superior: vozes e significados (Tese). Universidade Federal do Rio Grande do Sul, Porto Alegre.

Silva, D. S. (2013). Adequação curricular para o universitário cego: concepção, prática e desafios (Dissertação). Universidade Católica de Brasília, Brasília.

Silva Júnior, B. S. (2013). Fatores associados à conclusão da educação superior por cegos: um estudo a partir de L. S. Vygotski (Tese). Universidade Federal de Pelotas, Pelotas.

Touraine, A. (1999) Poderemos viver juntos? Iguais e diferentes. Petropólis: Vozes.

Vigotski, L. S. (1997). Obras escogidas V: fundamentos de defectología. Madrid: Visor.

Wallon, H. (1995). A evolução psicológica da criança. Lisboa: Edições 70.

O trabalho a ser enviado deverá: apresentar um resumo entre 200 e 300 palavras; ter texto entre 3000 e 4200 palavras, incluindo as referências bibliográficas; estar em formato Word, 


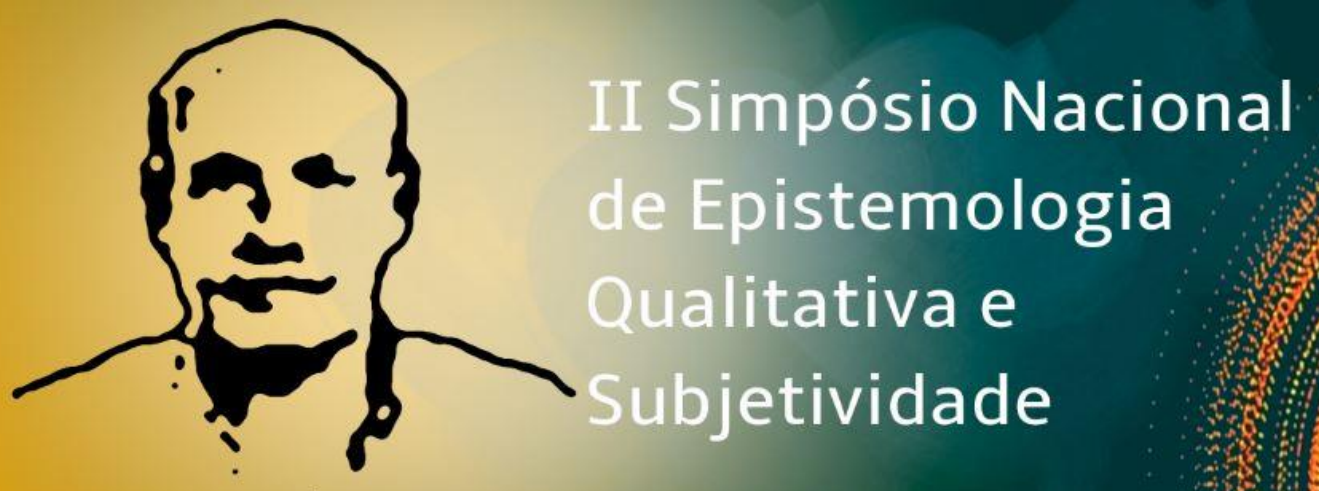

fonte Times New Roman, tamanho 12, espaço 1,5; seguir as normas da ABNT; incluir 3 (três) palavras-chave; finalizar com uma questão vinculada ao trabalho que contribua para o debate no Grupo de Discussão Temática.

\section{Referências}

